\title{
PHOTOGRAMMETRY FOR ARCHAEOLOGY: COLLECTING PIECES TOGETHER
}

\author{
A.G. Chibunichev ${ }^{1 *}$,V. A. Knyaz ${ }^{2,3}$, D.V. Zhuravlev ${ }^{4}$, V.M. Kurkov ${ }^{1}$ \\ ${ }^{1}$ Moscow State University of Geodesy and Cartography (MIIGAiK), Moscow, Russia - agchib@mail.ru \\ ${ }^{2}$ State Research Institute of Aviation System (GosNIIAS), Moscow, Russia - knyaz@ gosniias.ru \\ ${ }^{3}$ Moscow Institute of Physics and Technology (MIPT), Russia \\ ${ }^{4}$ State Historical Museum, Moscow, Russia - denzhuravlev@mail.ru
}

\section{Commission II, WG II/8}

KEY WORDS: archaeology, 3D reconstruction, calibration, data fusion, documenting, Bosporus archaeological expedition

\begin{abstract}
:
The complexity of retrieving and understanding the archaeological data requires to apply different techniques, tools and sensors for information gathering, processing and documenting. Archaeological research now has the interdisciplinary nature involving technologies based on different physical principles for retrieving information about archaeological findings. The important part of archaeological data is visual and spatial information which allows reconstructing the appearance of the findings and relation between them. Photogrammetry has a great potential for accurate acquiring of spatial and visual data of different scale and resolution allowing to create archaeological documents of new type and quality.

The aim of the presented study is to develop an approach for creating new forms of archaeological documents, a pipeline for their producing and collecting in one holistic model, describing an archaeological site. A set of techniques is developed for acquiring and integration of spatial and visual data of different level of details. The application of the developed techniques is demonstrated for documenting of Bosporus archaeological expedition of Russian State Historical Museum.
\end{abstract}

\section{INTRODUCTION}

The particularity of an archaeological investigation consists of an extended period of the research process (several years and more) and step-by-step excavating of new sites, the old ones losing their original state due to extracting findings for storing and exhibiting them in museums. So the holistic picture of a site is not always clear for a researcher. To preserve the structure of an archaeological site and possible relations between objects, found at different stages of archaeological excavation it is necessary to create an information model of a site which could be upgraded during a research and expanded with new findings and data. An approach for creating such information model is developed for documenting Bosporus archaeological expedition of Russian State Historical Museum (Schlotzhauer and Zhuravlev, 2013).

Modern techniques of archaeological research usually start from a geomagnetic investigation of a site to highlight areas of probable location of archaeological objects. This information should have accurate geo-referencing for preparing a plan of excavations.

Then the areas included in the plan are excavated sequentially and are documented using available means. Often the documenting includes only taking photographs of a found object with some scale object and some description of place and circumstances of finding. Usual types of documents for findings are shown in Figure 1.

The proposed approach combines a set of photogrammetric techniques for obtaining geometrical and visual information at different scales and detailing and a new approach for archaeological data analysis, fusion and presenting (Knyaz et al., 2017). The

\footnotetext{
${ }^{*}$ Corresponding author
}

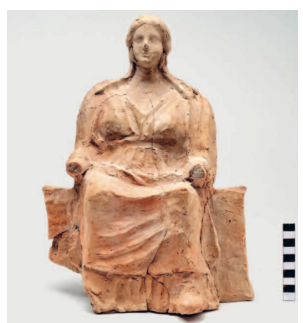

(a) terracotta goddess

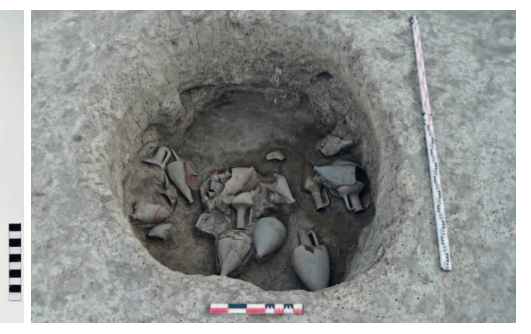

(b) amphoras
Figure 1. Examples of standard documents

whole archaeological site is considered as a unified cluster containing a set of objects which have relations between each other of different level of correlation. So when acquiring data, it is important to take into account all information about every artifact such as position in reference coordinate system, orientation, relative position in a group of objects, level of cultural layer, etc.

\section{RELATED WORK}

Nowadays a growing number of research and publications in the area of digital documenting for archaeology and cultural heritage demonstrates the importance and interest of this topic. The available tools for producing accurate and realistic 3D models created a background for performing a large number of projects in the area of archaeology resulting in digital models of high quality and details (Al-Hanbali et al., 2006), (Gruen, 2009), (Dall'Asta et al., 2016), (Clarke, 2016) and even for underwater environment (Bruno et al., 2015), (L'Hour and Creuze, 2016). From the other side, the rising amount of new digital documents produced the demand for developing standards for this new types of data (López-Menchero Bendicho et al., 2017), (Nicolae et al., 2014). 
The first applications of computer data processing in archaeology (Richards, 1998) demonstrated their high potential for actual and accurate documenting. Now the current tools and techniques for archaeological data recording allow generating high-quality documents (as in 2D, as in 3D) which contain as an accurate geometry of an object as a high-resolution photorealistic texture. This data could be used in wide variety of applications beginning with archaeological research and documenting(Callieri et al., 2011), (Tal, 2014), (Neumüller et al., 2014), and completing with virtual and augmented reality systems(Bianchini et al., 2014), (Botrugno et al., 2017), (Garstki, 2017) for studying(Schöning and Heidemann, 2015), (Barceló, 2010), (Kadar and Muntean, 2014) and visualization(Murgatroyd, 2013), (Tsipidis et al., 2011) of findings.

Although new types of archaeological documents become more available and easy to generate they are not still widely used in the current practice of archaeology for some reasons. Among them are "historical traditions" of archaeological documenting, relatively high cost of producing new 3D content (for device price and staff qualification), and "the difficulty to integrate 3D worlds with other more standard 2D material"(Remondino and Rizzi, 2010) . Nevertheless, the availability of new tools for documenting creates, firstly, the expanding amount of new quality data for archaeological analysis and, secondly, forces the researchers to develop new models of this data and new methods for this data processing (Wagtendonk et al., 2009), (Eppich and Almagro Vidal, 2013), (Pollefeys et al., 2001), (Berndt et al., 2010) .

\section{APPROACH TO ARCHAEOLOGICAL DATA ACQUIRING AND FUSION}

The progress in means for archaeological data retrieving and the growing amount of data of various types require standardization and systematization of the acquired data. And if some steps toward standardization are made (Remondino and Rizzi, 2010), (Gkadolou and Prastacos, 2016), the form of systematization depends on system purposes and requirements to it. The formulation of objectives and needs to archaeological information allows creating conceptual model of an information system.

Presented work is devoted to developing a conceptual model of an archaeological information system which is intended for supporting complex interdisciplinary research in archaeology. It has to apply new techniques and technologies for creating a holistic representation of archaeological site allowing to register as accurate as possible all findings along with their initial appearance, position, orientation and some other attributes.

So a set of different levels of an archaeological site representation is introduced. At the first level, a geo-referenced site 3D model is generated using satellite imagery and geomagnetic survey. This level is used for excavation planning and managing data in a unified system of coordinates. The second level represents an area of local excavation which is performed during the one epoch of archaeological site survey. At this level, a 3D model is produced using imagery acquired by a camera mounted on an unmanned aerial vehicle (UAV). The next level is object (finding) level. At this level, accurate textured 3D models of objects (or pieces of a found object) are created. A set of photorealistic textures is generated corresponding to a stage of artifact processing (as it was found, after dust removing, after gathering from pieces).

Along with creating 3D models of different levels, the position and orientation of each finding are registered and transformed into one common system of coordinates for further analyzing the possible relation between objects. Also created 3D models have time attribute which allows to represent the archaeological site and to analyze archaeological data at different stages of the investigation.

A set of novel techniques is developed for creating and fulfilling such archaeological information model. It is based on photogrammetric methods for obtaining geometrical and visual information at different scales and detailing and involves new approaches for archaeological data analysis, fusion and representing.

\section{TECHNIQUES FOR CAPTURING DIFFERENT TYPES OF INFORMATION}

\subsection{Satellite imagery}

A set of data acquisition techniques is developed for capturing different types of information. At the most common level a 3D model of the archeological site is produced by processing satellite imagery. Stereo pair of SPOT-6 images was used for producing digital elevation model for the area of interest (Table 1).

\begin{tabular}{ccc}
\hline \hline Type & ID & Date \\
\hline SPOT6 & DS-... 0818391-... -E037N45-01709 & $2013 / 10 / 24$ \\
\hline SPOT6 & DS-... 0818545-... -E037N45-01709 & $2013-10-24$ \\
\hline \hline
\end{tabular}

Table 1. Stereo pair of SPOT-6 images

SPOT6 color (RGB) images cover the area of 330 square kilometers of the Taman peninsula region (Figure 2), having resolution of $1.5 \mathrm{~m}$.

\subsection{UAV imagery}

At the next level of model detailing an aerial imaging by UAVbased digital camera is performed.

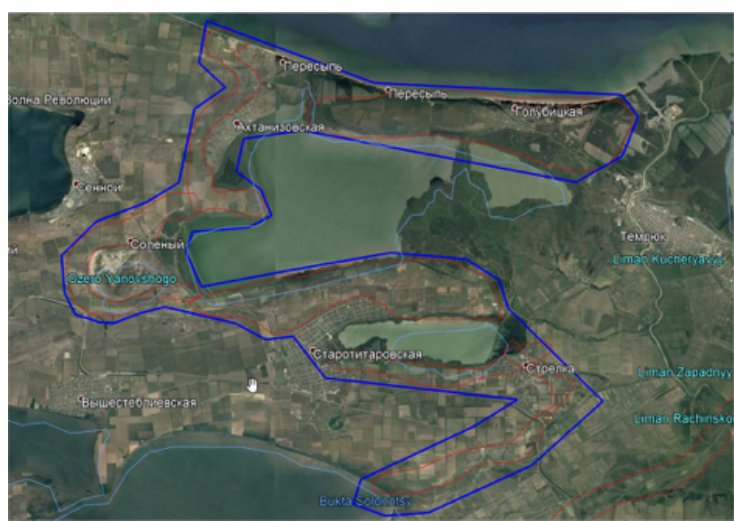

Figure 2. scheme of UAV survey

An aerial survey of the study area was performed using Geoscan 101 unmanned aerial vehicle (Figure 3). The Geoscan 101 is a flying-wing type unmanned aerial vehicle, equipped with electric motor. It starts from a catapult and it uses a parachute for landing. The Geoscan 101 is equipped with Sony DSC-RX1 digital camera with Carl Zeiss Sonnar T* 2/35mm (fixed) lens.

The main specifications of the Geoscan 101 and Sony DSC-RX1 camera are presented in Table 2. 


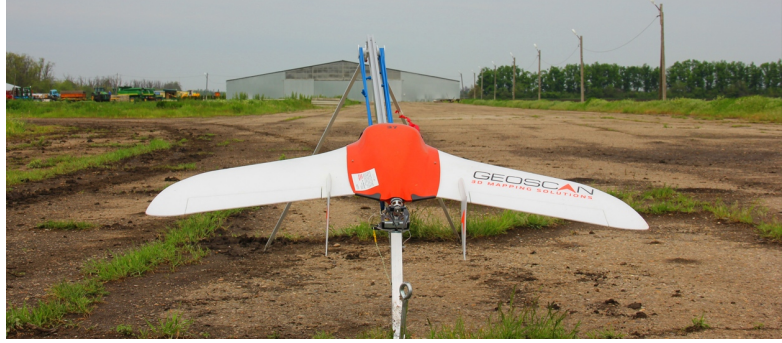

Figure 3. Unmanned aerial vehicle GeoScan 101

\begin{tabular}{|l|r|}
\hline UAV & Geoscan 101 \\
\hline \hline Wingspan & $1300 \mathrm{~mm}$ \\
\hline Take-off weight & $2.5 \mathrm{~kg}$ \\
\hline Flying time & $72 \mathrm{~km} / \mathrm{h}$ \\
\hline Cruising speed & Sony DSC-RX1 \\
\hline \hline On-board camera & CMOS \\
\hline Sensor Type & $35 \mathrm{~mm}$ \\
\hline Sensor Format & $35.80 \mathrm{~mm} \times 23.90 \mathrm{~mm}$ \\
\hline Sensor size & 5.97 microns \\
\hline Approximate Pixel Pitch & \\
\hline \hline
\end{tabular}

Table 2. Main specifications of the Geoscan $101 \mathrm{UAV}$

Preliminary calibration was performed for estimating interior orientation parameters of the camera. The laboratory photogrammetric calibration was carried out using special test field and original calibration software (Chibunichev et al., 2016). The field camera calibration was performed at specially designed testing ground with the size of $1000 \mathrm{~m} \times 1000 \mathrm{~m}$ and height differences of $80 \mathrm{~m}$. The testing ground has 51 targeted GPCs. The parameters of the photogrammetric distortion were determined from the results of the aerial triangulation with self-calibration. The results of the laboratory and field camera calibrations are presented in Table 3.

\begin{tabular}{|l|r|}
\hline Parameter & Value \\
\hline Focal length & $5704.67 \mathrm{pix}$ \\
Pixel size & $6 \times 6 \mu \mathrm{m}$ \\
Image size & $6,000 \times 4000 \mathrm{pix}$ \\
Principal point offset $(x, y)$ & $(9.536,22.355) \mathrm{pix}$ \\
\hline Radial distortion & \\
$R_{1}$ & -0.11155 \\
$R_{2}$ & 0.578603 \\
$R_{3}$ & -2.87085 \\
$R_{4}$ & 4.2585 \\
\hline Tangential distortion & \\
$P_{1}$ & -0.000173695 \\
$P_{2}$ & 0.00051821 \\
$P_{3}$ & 0 \\
$P_{4}$ & 0 \\
\hline Affinity and non-orthogonality & \\
$B_{1}$ & 1.21642 \\
$B_{2}$ & -0.0101437 \\
\hline
\end{tabular}

Table 3. Main specifications of the Geoscan $101 \mathrm{UAV}$

The following camera settings were used during aerial surveying: (1) lens locked to focus to infinity; (2) shutter priority $1 / 1000$ and 1/800 s for sunny and cloudy weather, respectively; (3) aperture and ISO sensitivity values selected automatically. Agisoft PhotoScan software was used for photogrammetric processing of UAV imagery (Florinsky et al., 2014).

\subsection{Ground survey}

For 3D reconstruction from ground-aquired imagery an original algorithm of Structure from Motion technique (Knyaz and Zheltov, 2017) was applied. It includes the following steps:

- Evaluation of camera model parameters (camera calibration)

- Detecting and identifying of corresponding points of a scene in the image sequence

- Estimation of the external orientation parameters for the images

- Calculation of spatial coordinates for detected point

- Dense 3D model reconstruction of the scene

Firstly, corresponding points are detected in a given set of the acquired images. Then two initial images from the acquired image sequence with high overlapping (60-70\%) are selected, providing a sufficient stereo basis. For the selected stereo pair a relative orientation is carried out using detected corresponding points. The spatial coordinates in the basis coordinate system for corresponding points visible in these images are calculated using determined relative orientation parameters of the images.

Then for the next image in the sequence, an exterior orientation is performed using the image coordinates of the detected points and the points spatial coordinates found at the previous step. The spatial coordinates of new detected points visible in the current image and in the previous image are calculated using the determined parameters of the exterior orientation. The new calculated $3 \mathrm{D}$ points are added to the $3 \mathrm{D}$ model. Also, spatial coordinates of previously calculated points are re-calculated using corrected exterior orientation parameters. Then the procedure for exterior orientation and adding points is repeated.

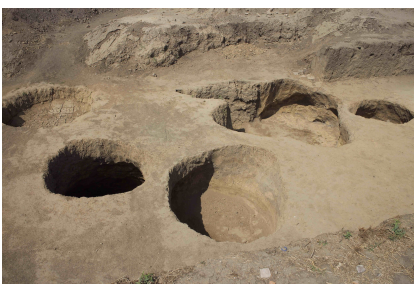

(a) Image of excavation site

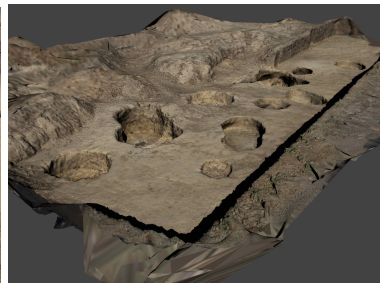

(b) 3D model of excavation site
Figure 4. SfM 3D reconstruction

Such procedure does not require global adjustment of the estimating parameters; instead, the process of images exterior orientation is iteratively performed. AN image from a sequence used for 3D reconstruction and the resulting excavation $3 \mathrm{D}$ model obtained by the described technique are shown in Figure 4.

\subsection{D scanning}

At the next level of data acquisition by 3D scanning system is used for generating accurate 3D models of artifacts and detailed 3D models of environment (Figure ??b). Also a set of high resolution color images is acquired for photorealistic presentation of the 3D models. To provide accurate positioning of finding relatively reference coordinate system special coded targets are used. This approach allows to combine all data in unified archaeological information model with the possibility of expanding with the new sets and new types of data. 
For generation $3 \mathrm{D}$ models at the object level an original photogrammetric system is used. It was designed for acquiring accurate 3D models of complex objects (Knyaz and Chibunichev, 2016) and for current research is upgraded by including high resolution digital camera for accurate photorealistic texturing of the produced 3D model. The 3D scanning system (figure 5a) includes:

- two high-resolution monochrome cameras for non-contact photogrammetric measurements;

- PC controlled structured light projector for automated correspondence problem solution;

- digital high resolution camera for automated photorealistic texture generation.

The main specifications of the photogrammetric system are presented in Table 4.

\begin{tabular}{|l|r|}
\hline Camera & Basler A641f \\
\hline Resolution & $1624 \mathrm{px} \times 1236 \mathrm{px}$ \\
\hline Pixel Size & $4.4 \mu \mathrm{m} \times 4.4 \mu \mathrm{m}$ \\
\hline Mono/ Color & Mono \\
\hline Sensor type & Progressive scan CCD \\
\hline Frame Rate & IEEE 1394a \\
\hline Interface & Canon 1000D \\
\hline \hline DSLR camera & $3888 \mathrm{px} \times 2592 \mathrm{px}$ \\
\hline Resolution & Color \\
\hline Sensor Size & $22.2 \mathrm{~mm} \times 14.8 \mathrm{~mm}$ \\
\hline Mono/ Color & BenQ W1000 \\
\hline Interface & HD, 1920 x 1080 \\
\hline \hline Projector & $5000: 1$ \\
\hline Resolution & \\
\hline Contrast Ratio & \\
\hline
\end{tabular}

Table 4. Main specifications of the photogrammetric system

Original procedure of photogrammetric system calibration provides high accuracy of generated 3D models and accurate texture mapping. The calibration procedure is fully automated due to applying original coded targets for reference points marking and using positioning stage for acquiring different views of a test field needed for interior parameters estimation.

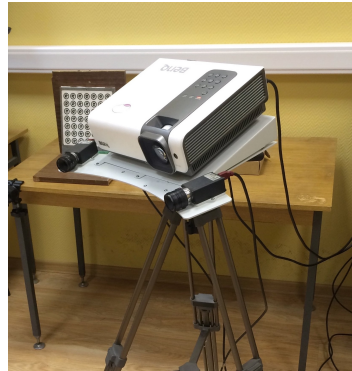

(a) photogrammeric system

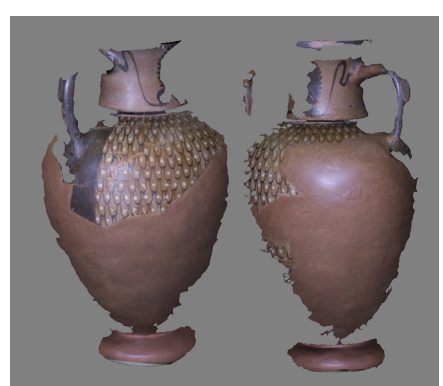

(b) textured scans
Figure 5. 3D scanning system and textured scans

For calibration about 20 images of test field at various position and orientation are acquired for each camera (two monochrome videocameras and digital color camera). The vector of estimated parameters $v_{e}^{l}=\left(x_{p}, y_{p}, m_{x}, m_{y}, a_{0}, \ldots, a_{5}\right)^{T}$ for test field calibration includes coordinates of principal point $\left(x_{p}, y_{p}\right)$, image scales $m_{x}, m_{y}$ and additional parameters $a_{0}, \ldots, a_{5}$ correspondingly. Additional parameters describing a distortion was taken in form (Beyer, 1992):

$$
\begin{aligned}
& \Delta x=a_{0} \cdot y_{a}+x_{a}\left(a_{1} r^{2}+a_{2} r^{4}+a_{3} r^{6}\right) \\
& \quad+a_{4}\left(r^{2}+2 x_{a}^{2}\right)+2 a_{5} x_{a} y_{a} \\
& \begin{aligned}
\Delta y & =a_{0} \cdot x_{a}+y_{a}\left(a_{1} r^{2}+a_{2} r^{4}+a_{3} r^{6}\right) \\
& +a_{5}\left(r^{2}+2 y_{a}^{2}\right)+2 a_{4} x_{a} y_{a} ;
\end{aligned} \\
& r^{2}=x_{a}^{2}+y_{a}^{2}
\end{aligned}
$$

where

Here $x_{a}, y_{a}$ are image coordinates of a point, $a_{0}, \ldots, a_{5}$ are camera's interior orientation parameters:

$a_{0}$ - coefficient of affine distortion;

$a_{1}, a_{2}, a_{3}$ - coefficients of radial distortion;

$a_{4}, a_{5}$ - coefficients of tangential distortion.

The calibration procedure provides the accuracy of $3 \mathrm{D}$ reconstruction at the level of 1:5000 (about $0.05 \mathrm{~mm}$ for working space of $300 \mathrm{~mm} \times 300 \mathrm{~mm} \times 300 \mathrm{~mm}$ ).

A set of partial scans are acquired for accurate object 3D reconstruction. Then they are transformed in a common system of coordinates using iterative closest point algorithm. A sample of several partial scans and the result of 3D reconstruction and photorealistic texture mapping are presented in figure 6 . (a) $2.5 \mathrm{D}$ fragments

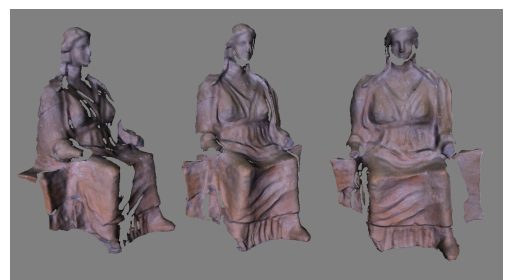

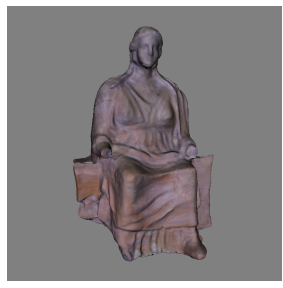

(b) 3D model
Figure 6. Textured 2.5D fragments and 3D model of terracotta figurine

\subsection{Data integration}

The archaeological data acquired at different levels of detailing has to be integrated into single holistic model containing information about position, orientation, appearance and some other features of findings. To combine data of different levels of detailing it is required to match objects and features of different scales and resolution.

For establishing a correspondence between models of different levels, two main approaches are developed. The first method is based on using coded targets which allow to detect and to identify the reference points automatically for transformation into one reference coordinate system. For automatic identification of a given point marked by a coded target in images of different scales, multi-scale coded targets are developed. They use a target of low scale as a center of a large-scale target. Since the center of a 
coded target is determined using the inner border of the first black ring, it can be precisely found in the images of different scales.

The second technique uses UAV images for estimating the position and orientation of detailed 3D model generated by 3D scanning. As a result of UAV imagery processing for creating a 3D model of an archaeological site, the external orientations of all processed images are known. And since the resolution of these images is high, they are used for determining the accurate position and orientation of detailed 3D models presenting in these images. Corresponding points in a texture of a 3D model and in UAV image are found using feature descriptor, accurate texture mapping providing knowing of spatial coordinates of the 3D model.

\section{CONCLUSION}

An approach is developed for data acquiring, structuring and integration for the documenting of the archaeological study. It is based on a set of photogrammetric techniques for capturing and fusion different types of archaeological information. The basic digital elevation model of a region of archaeological study is produced by processing satellite imagery. Then UAV-based aerial survey survey is carried out for obtaining mode detailed 3D model of the excavation areas. The UAV imagery is processed by original software which implements an original technique for photorealistic 3D reconstruction of the archaeological site.

At the next level of data acquisition, 3D scanning techniques are implemented for generating detailed 3D models of an excavation. The original photogrammetric system allows producing accurate photorealistic 3D models of artifacts in an automated mode. A set of high-resolution color images is used for accurate texture mapping and photorealistic presentation of 3D models.

The developed techniques were applied during Bosporus archaeological expedition of Russian State Historical Museum. A set of 3D models of different scales and resolution is created. It serves as the basis for the developing archaeological information model Bosporus Kingdom.

\section{ACKNOWLEDGEMENTS}

The work was performed with the support by Grant 17-29-04410 of Russian Foundation for Basic Research (RFBR).

\section{REFERENCES}

Al-Hanbali, N., Al Bayari, O., Saleh, B., Almasri, H. and Baltsavias, E., 2006. Macro to Micro Archaeological Documentation: Building a 3D GIS Model for Jerash City and the Artemis Temple. Springer Berlin Heidelberg, Berlin, Heidelberg, pp. 447-468.

Barceló, J. A., 2010. Visual Analysis in Archaeology. An Artificial Intelligence Approach. Springer Berlin Heidelberg, Berlin, Heidelberg, pp. 93-156.

Berndt, R., Buchgraber, G., Havemann, S., Settgast, V. and Fellner, D. W., 2010. A Publishing Workflow for Cultural Heritage Artifacts from 3D-Reconstruction to Internet Presentation. Springer Berlin Heidelberg, Berlin, Heidelberg, pp. 166-178.

Beyer, H., 1992. Advances in characterization and calibration of digital imaging systems. Int. Arch. Photogramm. Remote Sens. Spatial Inf. Sci. XXIX pp. 545-555.
Bianchini, C., Borgogni, F., Ippolito, A. and Senatore, L. J., 2014. The Surveying and Representation Process Applied to Archaeology: A Quest for Invariants in a Highly Variable Context. Springer International Publishing, Cham, pp. 1-29.

Botrugno, M. C., D’Errico, G. and De Paolis, L. T., 2017. Augmented Reality and UAVs in Archaeology: Development of a Location-Based AR Application. Springer International Publishing, Cham, pp. 261-270.

Bruno, F., Lagudi, A., Gallo, A., Muzzupappa, M., Davidde Petriaggi, B. and Passaro, S., 2015. 3d documentation of archeological remains in the underwater park of baiae. ISPRS - International Archives of the Photogrammetry, Remote Sensing and Spatial Information Sciences XL-5/W5, pp. 41-46.

Callieri, M., Dell'Unto, N., Dellepiane, M., Scopigno, R., Soderberg, B. and Larsson, L., 2011. Documentation and interpretation of an archeological excavation: An experience with dense stereo reconstruction tools. In: Proceedings of the 12th International Conference on Virtual Reality, Archaeology and Cultural Heritage, VAST'11, Eurographics Association, Aire-laVille, Switzerland, Switzerland, pp. 33-40.

Chibunichev, A. G., Kurkov, V. M., Smirnov, A. V., Govorov, A. V. and Mikhalin, V. A., 2016. Investigation of phototriangulation accuracy with using of various techniques laboratory and field calibration. ISPRS - International Archives of the Photogrammetry, Remote Sensing and Spatial Information Sciences XLI-B1, pp. 1227-1233.

Clarke, J. R., 2016. 3D Model, Linked Database, and BornDigital E-Book: An Ideal Approach to Archaeological Research and Publication. Springer International Publishing, Cham, pp. 136-145.

Dall'Asta, E., Bruno, N., Bigliardi, G., Zerbi, A. and Roncella, R., 2016. Photogrammetric techniques for promotion of archaeological heritage: The archaeological museum of parma (italy). ISPRS - International Archives of the Photogrammetry, Remote Sensing and Spatial Information Sciences XLI-B5, pp. 243-250.

Eppich, R. and Almagro Vidal, A., 2013. Challenges, strategies and techniques for international training in technology for cultural heritage conservation. ISPRS Annals of Photogrammetry, Remote Sensing and Spatial Information Sciences II-5/W1, pp. 109-114.

Florinsky, I. V., Kurkov, V. M. and Bliakharskii, D. P., 2014. Geomorphometry from unmanned aerial surveys. Transactions in GIS 22(1), pp. 58-81.

Garstki, K., 2017. Virtual representation: the production of $3 \mathrm{~d}$ digital artifacts. Journal of Archaeological Method and Theory 24(3), pp. 726-750.

Gkadolou, E. and Prastacos, P., 2016. Documentation of cultural heritage sites using the inspire directive. Proc. SPIE 9688, pp. 968811-968811-10.

Gruen, A., 2009. Virtual Archaeology - New Methods of ImageBased 3D Modeling. Springer Berlin Heidelberg, Berlin, Heidelberg, pp. 287-305.

Kadar, M. and Muntean, M., 2014. A Collaborative Environment for E-training in Archaeology. Springer International Publishing, Cham, pp. 303-312.

Knyaz, V. A. and Chibunichev, A. G., 2016. Photogrammetric techniques for road surface analysis. ISPRS - International Archives of the Photogrammetry, Remote Sensing and Spatial Information Sciences XLI-B5, pp. 515-520. 
Knyaz, V. and Zheltov, S., 2017. Accuracy evaluation of structure from motion surface $3 \mathrm{~d}$ reconstruction. Proc.SPIE 10332, pp. $10332-10332-10$.

Knyaz, V., Chibunichev, A. and Zhuravlev, D., 2017. Multisource data fusion for documenting archaeological sites. Proc.SPIE 10427, pp. $10427-10427-9$.

L'Hour, M. and Creuze, V., 2016. French Archaeology's Long March to the Deep-The Lune Project: Building the Underwater Archaeology of the Future. Springer International Publishing, Cham, pp. 911-927.

López-Menchero Bendicho, V. M., Flores Gutiérrez, M., Vincent, M. L. and Grande León, A., 2017. Digital Heritage and Virtual Archaeology: An Approach Through the Framework of International Recommendations. Springer International Publishing, Cham, pp. 3-26.

Murgatroyd, P., 2013. Visualising Large-Scale Behaviours: Presenting 4D Data in Archaeology. Springer London, London, pp. 259-274.

Neumüller, M., Reichinger, A., Rist, F. and Kern, C., 2014. $3 D$ Printing for Cultural Heritage: Preservation, Accessibility, Research and Education. Springer Berlin Heidelberg, Berlin, Heidelberg, pp. 119-134.

Nicolae, C., Nocerino, E., Menna, F. and Remondino, F., 2014. Photogrammetry applied to problematic artefacts. ISPRS - International Archives of the Photogrammetry, Remote Sensing and Spatial Information Sciences XL-5, pp. 451-456.

Pollefeys, M., Van Gool, L., Vergauwen, M., Cornelis, K., Verbiest, F. and Tops, J., 2001. Image-based 3d acquisition of archaeological heritage and applications. In: Proceedings of the 2001 Conference on Virtual Reality, Archeology, and Cultural Heritage, VAST '01, ACM, New York, NY, USA, pp. 255-262.

Remondino, F. and Rizzi, A., 2010. Reality-based 3d documentation of natural and cultural heritage sites-techniques, problems, and examples. Applied Geomatics 2(3), pp. 85-100.

Richards, J. D., 1998. Recent trends in computer applications in archaeology. Journal of Archaeological Research 6(4), pp. 331382 .

Schlotzhauer, U. and Zhuravlev, D., 2013. Forschungen in der antiken siedlung golubickaja-2 auf der sudrussischen tamanhalbinsel. archaologie geoarchaologie historische interpretation. Eurasia Antiqua 19, pp. 105-125.

Schöning, J. and Heidemann, G., 2015. Evaluation of Multi-view $3 D$ Reconstruction Software. Springer International Publishing, Cham, pp. 450-461.

Tal, A., 2014. 3D Shape Analysis for Archaeology. Springer Berlin Heidelberg, Berlin, Heidelberg, pp. 50-63.

Tsipidis, S., Koussoulakou, A. and Kotsakis, K., 2011. Geovisualization and Archaeology: supporting Excavation Site Research. Springer Berlin Heidelberg, Berlin, Heidelberg, pp. 85-107.

Wagtendonk, A. J., Verhagen, P., Soetens, S., Jeneson, K. and de Kleijn, M., 2009. Past in Place: The Role of Geo-ICT in Present-day Archaeology. Springer Netherlands, Dordrecht, pp. 59-86. 